\title{
Simultaneous Measurements of Specific Heat, Electrical Resistivity, and Hemispherical Total Emittance by a Pulse Heating Technique: Hafnium-3 (Wt. \%) Zirconium, 1500 to $2400 K^{*}$
}

\author{
A. Cezairliyan and J. L. McClure \\ Institute for Materials Research, National Bureau of Standards, Washington, D.C. 20234
}

(December 20, 1974)

\begin{abstract}
Simultaneous measurements of specific heat, electrical resistivity and hemispherical total emittance of hafnium containing 3.12 weight percent zirconium in the temperature range 1500 to $2400 \mathrm{~K}$ by a subsecond duration, pulse heating technique are described. The measurements indicate decreases in specific heat (by about 13\%) and in electrical resistivity (by about $8 \%$ ) as the result of the $\alpha \rightarrow \beta$ transformation. Estimated inaccuracies of the measured properties are: 3 percent for specific heat, 1 percent for electrical resistivity and 5 percent for hemispherical total emittance.
\end{abstract}

Key words: Electrical resistivity; emittance; hafnium; high-speed measurements; high temperatures; specific heat; thermodynamics.

\section{Introduction}

In this paper, application of a pulse heating technique to the simultaneous measurements of specific heat, electrical resistivity and hemispherical total emittance of hafnium containing 3.12 weight percent zirconium in the temperature range 1500 to $2400 \mathrm{~K}$ is described. For simplicity, in the paper this substance will be referred to as hafnium-3 (wt. \%) zirconium. The measurements are of particular interest in view of the fact that hafnium undergoes a solid-solid phase transformation (from hexagonal close-packed to bodycentered cubic) in this range.

The method is based on rapid resistive self-heating of the specimen from room temperature to high temperatures (above $1500 \mathrm{~K}$ ) in less than one second by the passage of an electrical current pulse through it; and on measuring, with millisecond resolution, such experimental quantities as current through the specimen, potential drop across the specimen, and specimen temperature. Details regarding the construction and operation of the measurement system, the methods of measuring experimental quantities, and other pertinent information, such as the formulation of relations for properties, error analysis, etc., are given in earlier publications $[1,2] .^{1}$

\footnotetext{
*This work was supported in part by the U.S. Air Force Office of Scientific Research. ${ }^{1}$ Figures in brackets indicate the literature references at the end of this paper.
}

In the following sections of this paper a tabular format is adopted in presenting information on the specimen, measurements, system characteristics, results and errors.

\section{Measurements}

The details regarding the hafnium-3 (wt. \%) zirconium specimens used in the present measurements are given in table 1. A summary of the measurement technique and the operational characteristics of the system is given in table 2 . The polynomial functions (obtained by the least squares method) that represent the experimental results of specific heat and electrical resistivity are given in table 3 . The values of properties at 100 degree temperature intervals computed using the functions are presented in table 4 . The experimental results are presented in the appendix. Each number tabulated in the appendix represents results from over 50 original data points. The results of hemispherical total emittance are given in table 7. An estimate of errors in the measured and computed quantities is given in table 5 . All values reported in this paper are based on the International Practical Temperature Scale of 1968 [3]. In all computations, the geometrical quantities are based on their room temperature (298 K) dimensions. 
TABLE 1. Specimen information

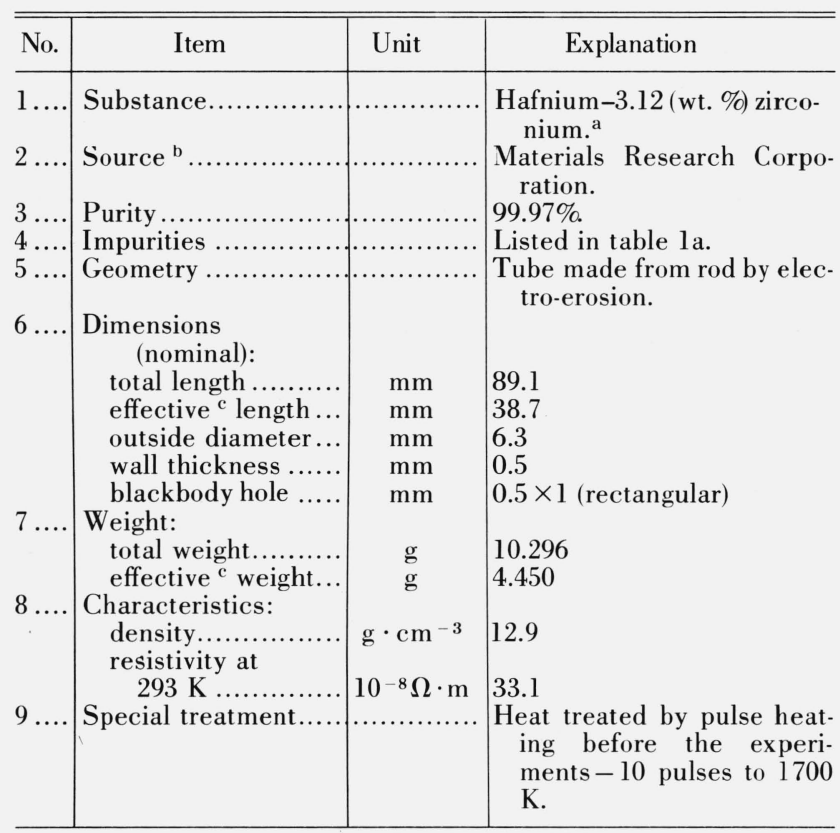

a The analysis to determine the zirconium content was performed by the Spectrochemical Analysis Section at NBS.

b The supplier is identified in this paper in order to adequately characterize the specimen-Such an identification does not imply recommendation or endorsement by the National Bureau of Standards.

${ }^{c}$ Effective refers to the portion of the specimen between the voltage probes.

TABLE la. Impurities in the specimen ${ }^{\text {a }}$

(According to the manufacturer's analysis)

\begin{tabular}{l|c|c|c|c|c|c|c}
\hline \hline Element.............. & $\mathrm{C}$ & $\mathrm{O}$ & $\mathrm{N}$ & $\mathrm{Al}$ & $\mathrm{Ca}$ & $\mathrm{Cu}$ & $\mathrm{Fe}$ \\
ppm................ & 15 & 10 & 10 & 20 & 10 & 10 & $<50$ \\
\hline Element.............. & $\mathrm{Mn}$ & $\mathrm{Mo}$ & $\mathrm{Nb}$ & $\mathrm{Si}$ & $\mathrm{Ta}$ & $\mathrm{Ti}$ & $\mathrm{W}$ \\
$\operatorname{ppm} \ldots \ldots \ldots \ldots \ldots \ldots \ldots$ & 20 & 10 & 30 & 20 & 30 & 10 & 10 \\
\hline
\end{tabular}

${ }^{a}$ The total amount of all other detected elements is less than $70 \mathrm{ppm}$, each element being below $10 \mathrm{ppm}$ limit. 
TABLE 2. Measurement technique and system characteristics

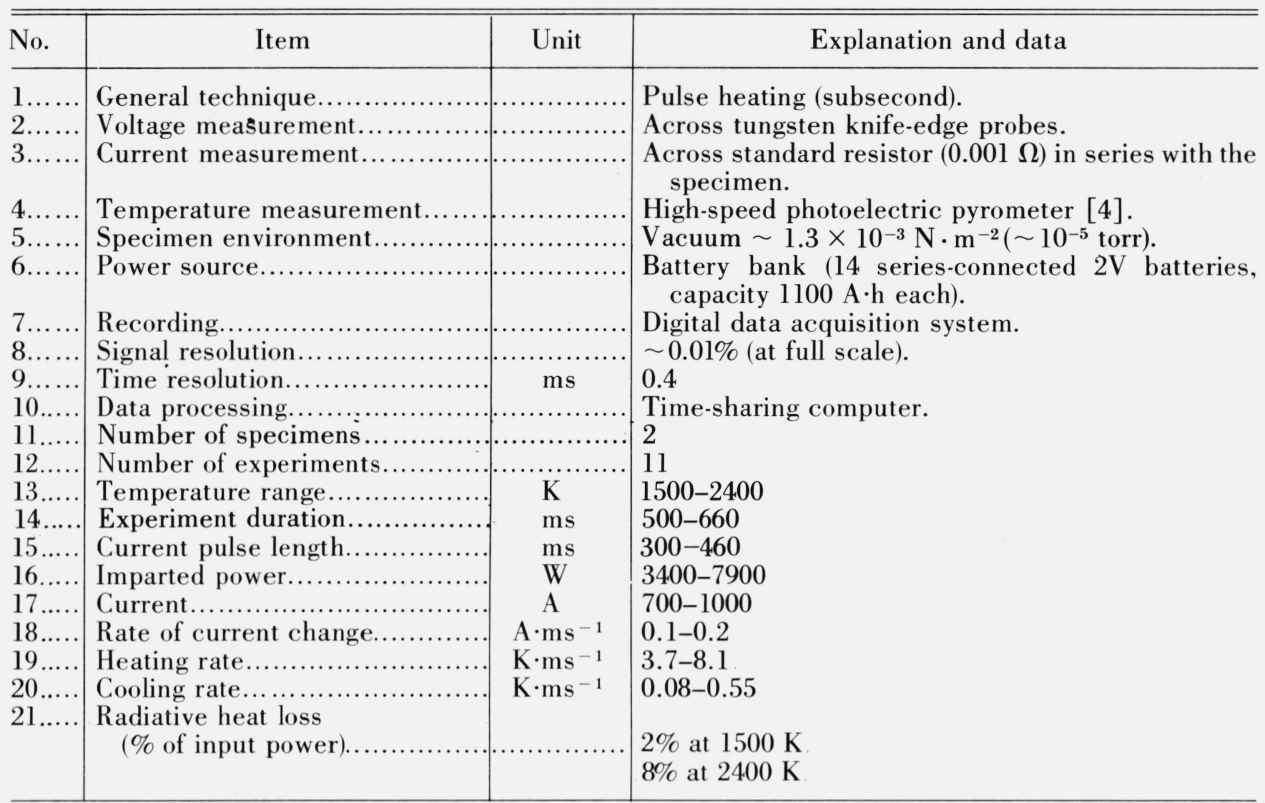

TABLE 3. Functional representation of the results on hafnium-3 (wt.\%) zirconium

\begin{tabular}{l|l|l}
\hline \hline Phase & \multicolumn{1}{|c|}{$\begin{array}{c}\text { Specific heat } \\
\left(\mathrm{J} \cdot \mathrm{g}^{-1} \cdot \mathrm{K}^{-1}\right)\end{array}$} & $\begin{array}{c}\text { Electrical resistivity } \\
\left(10^{-8} \Omega \cdot \mathrm{m}\right)\end{array}$ \\
\hline \multirow{5}{\alpha}{} & $1500<T<1850 \mathrm{~K}$ & $1500<T<2000 \mathrm{~K}$ \\
& $c_{p}=A+B T$ & $\rho=A+B T+C T^{2}$ \\
& $A=1.431 \times 10^{-1}$ & $A=46.936$ \\
& $B=3.830 \times 10^{-5}$ & $B=1.1967 \times 10^{-1}$ \\
& & $C=-3.0002 \times 10^{-5}$ \\
& $\sigma^{a}=0.3 \%$ & $\sigma^{\mathrm{a}}=0.2 \%$ \\
\hline \multirow{5}{*}{$\beta$} & $2150<T<2400 \mathrm{~K}$ & $2050<T<2400 \mathrm{~K}$ \\
& $c_{p}=A+B T+C T^{2}$ & $\rho=A+B T$ \\
& $A=0.4544$ & $A=130.47$ \\
& $B=-2.771 \times 10^{-4}$ & $B=1.1276 \times 10^{-2}$ \\
& $C=7.286 \times 10^{-8}$ & $\sigma^{\mathrm{a}}=0.2 \%$ \\
& $\sigma^{\mathrm{a}}=0.5 \%$ &
\end{tabular}

a Standard deviation as computed from the difference between the value of an experimental result (as tabulated in the appendix) and that from the smooth functions reported above.

TABLE 4. Results on properties of hafnium-3 (wt. \%) zirconium

\begin{tabular}{c|c|c|c}
\hline \hline Phase & $\begin{array}{c}T \\
(\mathrm{~K})\end{array}$ & $\begin{array}{c}c_{p} \\
\left(\mathrm{~J} \cdot \mathrm{g}^{-1} \cdot \mathrm{K}^{-1}\right)\end{array}$ & $\begin{array}{c}\rho \\
\left(10^{-8} \Omega \cdot \mathrm{m}\right)\end{array}$ \\
\hline \multirow{4}{*}{$\alpha$} & 1500 & 0.2006 & 158.94 \\
& 1600 & .2044 & 161.60 \\
& 1700 & .2082 & 163.67 \\
& 1800 & .2120 & 165.14 \\
& 1900 & - & 166.00 \\
& 2000 & - & 166.27 \\
\hline \multirow{4}{*}{$\beta$} & 2100 & - & 154.15 \\
& 2200 & 0.1974 & 155.28 \\
& 2300 & .2025 & 156.41 \\
& 2400 & .2090 & 157.53 \\
\hline
\end{tabular}

TABLE 5. Error analysis

\begin{tabular}{|c|c|c|}
\hline Quantity & Imprecision $^{\mathrm{a}}$ & Inaccuracy $^{b}$ \\
\hline Temperature (at $2000 \mathrm{~K}$ ).. & $0.5 \mathrm{~K}$ & $4 \mathrm{~K}$ \\
\hline 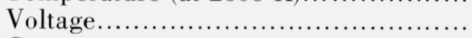 & $.03 \%$ & $0.1 \%$ \\
\hline Current............... & $.03 \%$ & $0.1 \%$ \\
\hline Specific heat............ & .5 & $3 \%$ \\
\hline Electrical resistivity $\ldots \ldots \ldots \ldots \ldots \ldots \ldots \ldots \ldots \ldots \ldots$ & .2 & $1 \%$ \\
\hline Hemispherical total emittance............ & & $5 \%$ \\
\hline
\end{tabular}

a Imprecision refers to the standard deviation of a quantity as computed from the difference between the value of the quantity and that from the smooth function obtained by the least squares method. The quantities in the case of temperature, voltage, and current are the individual points measured in a single experiment, and in the case of specific heat and electrical resistivity are the results from all experiments as tabulated in the appendix.

${ }^{b}$ Inaccuracy refers to the estimated total error (random and systematic).

\section{Discussion}

The specific heat and electrical resistivity of hafnium-3 (wt. \%) zirconium measured in this work are presented in figures 1 and 2 , respectively, and are compared graphically with the results reported in the literature on hafnium containing varying amounts of zirconium. The results reported in the literature were for temperatures below $2200 \mathrm{~K}$. In this work, the measurements were extended to $2400 \mathrm{~K}$, which is approximately $100 \mathrm{~K}$ below the melting point of hafnium. 


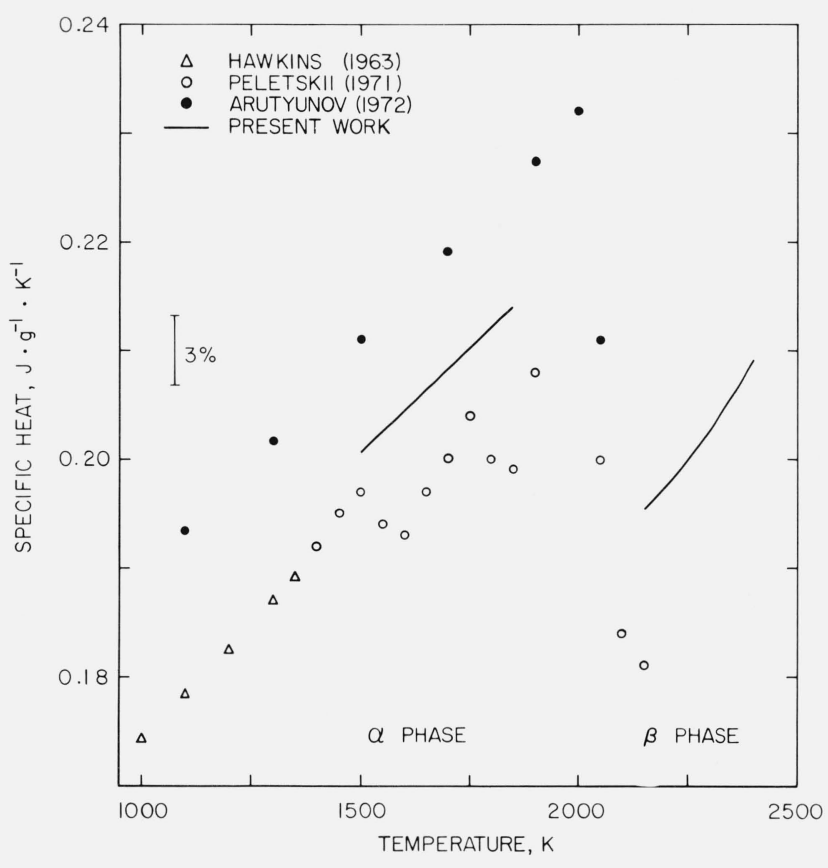

FIGURE 1. Specific heat of hafnium reported in the literature.

Zirconium content in weight percent is: 2.8, Hawkins et al [7]; 0.66. Peletskii and Druzhinin [6]; 0.65, Arutyunov et al [5]; and 3.12 present work.

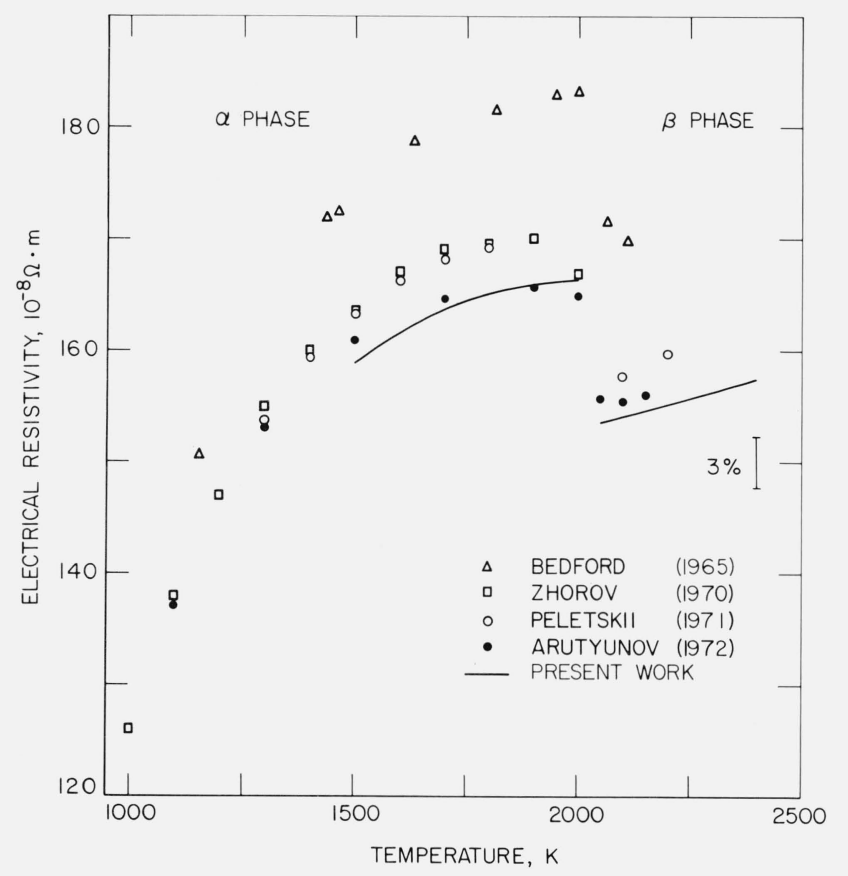

FigURE 2. Electrical resistivity of hafnium reported in the literature.

Zirconium content in weight percent is: 2.4, Bedford [9]; 0.96, Zhorov [8]; 0.66, Peletskii and Druzhinin [6]; 0.65 Arutyunov et al[5]; and 3.12 present work.

\subsection{Specific Heat}

Zirconium content (2.8 wt. \%) of the specimen used by Hawkins et al. [7] was comparable to that of the specimen used in the present work. Extrapolation of the results of Hawkins et al. from $1350 \mathrm{~K}$ to $1500 \mathrm{~K}$ yields a value which is approximately 2.5 percent lower than the present work result. Arutyunov et al. [5] and Peletskii and Druzhinin [6] have reported measurements using specimens with lower zirconium contentapproximately 0.65 (wt. \%) zirconium. However, their results are in considerable disagreement with each other (6 to $10 \%$ ). The results (after correcting for zirconium content) of the present work are about 5 percent lower than those of Arutyunov et al., and on the average about 4 percent higher than those of Peletskii and Druzhinin in the overlaping temperature regions below the transformation point. Above the transformation point, only a few measurements (all below $2200 \mathrm{~K}$ ) were reported by the above investigators. Because of the insufficient data, it was not possible for them to establish the trend of specific heat versus temperature in the range between the transformation and the melting points.

The results of the present work indicate the following trend for specific heat as a function of temperature: (1) before transformation-increases nearly linearly, (2) at the transformation point-decreases sharply, and (3) above the transformation point-increases with an increasing rate of change. Extrapolation of the results to the transformation temperature, $2012 \mathrm{~K}$ [10], indicates a change in specific heat of 12.9 percent $^{2}\left(0.0283 \mathrm{~J} \cdot \mathrm{g}^{-1} \cdot \mathrm{K}^{-1}\right)$ during the transformation. A similar procedure applied to the results reported in the literature yields the following approximate values for the change in specific heat during transformation: 13.0 percent (Peletskii and Druzhinin [6]) and 9.1 percent (Arutyunov et al. [5]). The latter is likely to be low since data did not extend beyond the initial transformation period.

Table 6 gives estimated results of the heat capacity of pure hafnium obtained from the present work data after making a correction for the zirconium content

TABLE 6. Heat capacity of pure hafnium

\begin{tabular}{c|c|c}
\hline \hline Phase & $\begin{array}{c}\text { Temperature } \\
(\mathrm{K})\end{array}$ & $\begin{array}{c}\text { Heat capacity } \\
\left(\mathrm{J} \cdot \mathrm{mol}^{-1} \cdot \mathrm{K}^{-1}\right)\end{array}$ \\
\hline \multirow{3}{*}{$\alpha$} & 1500 & 35.0 \\
& 1600 & 35.7 \\
& 1700 & 36.4 \\
& 1800 & 37.0 \\
\hline \multirow{3}{*}{$\beta$} & 2200 & 34.1 \\
& 2300 & 35.0 \\
& 2400 & 36.3 \\
\hline
\end{tabular}

${ }^{2}$ Computed according to the relation:

$$
\Delta c_{p}=100\left[\left(c_{p}\right)_{\text {before }}-\left(c_{p}\right)_{\text {after }}\right] /\left(c_{p}\right)_{\text {before }} .
$$


(using Kopp's additivity law). Heat capacity of zirconium needed for this correction is obtained from an earlier publication [11]. The atomic weight of hafnium was taken as 178.49 [13]. It may be seen that at $2400 \mathrm{~K}$ (about $100 \mathrm{~K}$ below its melting point), heat capacity of hafnium reaches a value of $36.3 \mathrm{~J} \cdot \mathrm{mol}^{-1} \mathrm{~K}^{-1}$, which is considerably higher than the Dulong and Petit value of $3 R\left(24.943 \mathrm{~J} \cdot \mathrm{mol}^{-1} \cdot \mathrm{K}^{-1}\right)$.

\subsection{Electrical Resistivity}

Electrical resistivity results for hafnium reported in the recent literature $[5,6,8,9]$, with one exception [9], are in agreement with those of the present work within 3 percent. The results of Bedford [9] are 5 to 10 percent higher than those of the other investigators. This difference cannot be attributed to the high value of zirconium content in the specimen (about 2.4 percent by weight), since the present work results, which were obtained on specimens of comparable composition, were lower than those of the other investigators. The zirconium content of specimens used by Arutyunov et al. [5] and Peletskii and Druzhinin [6] was about 0.65 percent by weight, while the specimen used by Zhorov [8] contained about 1 percent zirconium. The results of all the investigators show a decrease in electrical resistivity as the result of the $\alpha \rightarrow \beta$ transformation. However, because of the insufficient data, it was not possible to establish the trend of resistivity versus temperature in the range between the transformation and the melting points.

The results of the present work indicate the following trend for electrical resistivity as a function of temperature: (1) before transformation increases with a decreasing rate of change, (2) during transformation decreases sharply, and (3) after transformation increases with an increasing rate of change. Extrapolation of the results to the transformation temperature ${ }^{3}$ indicate a change in electrical resistivity of 7.9 percent $\left(13.1 \times 10^{-8} \Omega \cdot \mathrm{m}\right)$ during the transformation. The data reported in the literature yield the following results for the change in electrical resistivity during the transformation: 6.4 percent (Arutyunov et al. [5]), 6.9 percent (Peletskii and Druzhinin [6]), and 7.3 percent (Bedford [9]). Zhorov's measurements did not extend beyond the initial transformation period, thus it was not possible to obtain a meaningful result on resistivity change. Earlier measurements by Fast [12] of the resistance change in a hafnium specimen containing 3 weight percent zirconium during transformation yielded a value of 7.5 percent.

A distinct advantage of the method employed in this work is that it provides resistivity data during the

\footnotetext{
${ }^{3}$ Computed according to the relation:
}

$$
\Delta \rho=100\left(\rho_{\text {before }}-\rho_{\text {after }}\right) / \rho_{\text {before- }}
$$

entire transformation period. This allows the accurate determination of the variation of electrical resistivity as a function of time and temperature near and at the transformation point. The results of a typical experiment are shown in figures 3 and 4 .

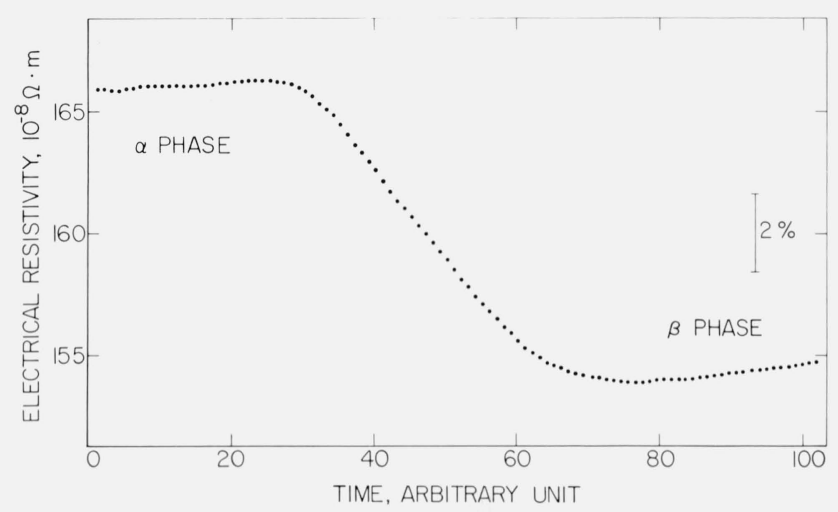

FIGURE 3. Variation of electrical resistivity as a function of time near and at the $\alpha \rightarrow \beta$ transformation point of hafnium-3 (wt \%) zirconium.

(The curve refers to specimen $1 ; 1$ time unit $=0.833 \mathrm{~ms}$ ).

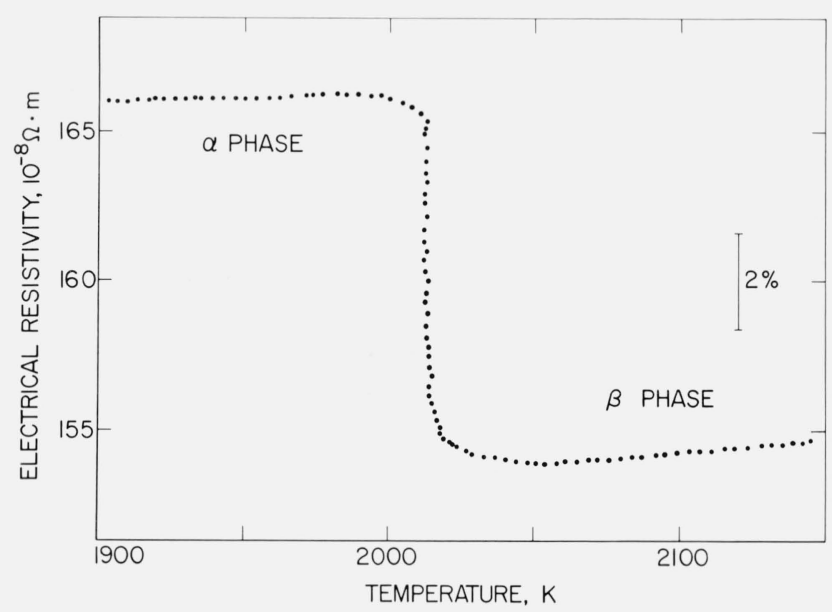

FIGURE 4. Variation of electrical resistivity as a function of temperature near and at the $\alpha \rightarrow \beta$ transformation point of hafnium-3 (wt \%) zirconium.

(The curve refers to specimen 1). 


\subsection{Hemispherical Total Emittance}

Hemispherical total emittance was measured at three temperatures, two below and one above the transformation point. A comparison of the present work results with those reported in the literature (table 7 ) shows a general agreement in the range 0 to 5 percent at temperatures 1700 and $1870 \mathrm{~K}$. No data was located in the literature for temperatures above $2200 \mathrm{~K}$. From the available data no satisfactory conclusion could be drawn regarding the effect of zirconium on the hemispherical total emittance of hafnium.
TABLE 7. Hemispherical total emittance of hafnium containing various amounts of zirconium as reported in the literature

\begin{tabular}{|c|c|c|c|c|c|}
\hline \multirow{2}{*}{ Investigator } & \multirow{2}{*}{ Ref. } & \multirow{2}{*}{$\begin{array}{c}\text { Zirconium } \\
\text { content } \\
\text { (wt. \%) }\end{array}$} & \multicolumn{3}{|c|}{ Temperature, $\mathrm{K}$} \\
\hline & & & 1700 & 1870 & 2280 \\
\hline Zhorov & [8] & 0.96 & 0.330 & 0.330 & 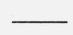 \\
\hline Peletskii and Druzhinin & [6] & 0.66 & .306 & .316 & 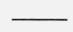 \\
\hline Arutyunov et al... & [5] & 0.65 & .312 & .323 & \\
\hline Present work.... & & 3.12 & .320 & .330 & 0.342 \\
\hline
\end{tabular}

\section{Appendix}

TABLE A-1. Experimental results on specific heat of hafnium-3 (wt \%) zirconium $^{\text {a }}$

\begin{tabular}{l|c|c|c|c|c|c|c}
\hline \hline \multirow{2}{*}{ Phase } & & \multicolumn{5}{|c|}{ Specimen-1 } & \multicolumn{2}{c}{ Semp. } \\
\cline { 3 - 7 } & $(\mathrm{K})$ & \multicolumn{2}{|c|}{ First heating } & \multicolumn{2}{c}{ Second heating } & \multicolumn{2}{c}{} \\
\cline { 3 - 7 } & & $c_{p}$ & $\Delta c_{p}$ & $c_{p}$ & $\Delta c_{p}$ & $c_{p}$ & $\Delta c_{p}$ \\
\hline \multirow{4}{*}{$\alpha$} & 1500 & 0.2012 & +0.32 & 0.2008 & +0.12 & 0.2002 & -0.17 \\
& 1550 & 0.2022 & -0.13 & 0.2031 & +0.31 & 0.2019 & -0.28 \\
& 1600 & 0.2044 & +0.01 & 0.2053 & +0.45 & 0.2042 & -0.09 \\
& 1650 & 0.2062 & -0.04 & 0.2066 & +0.15 & 0.2060 & -0.14 \\
& 1700 & 0.2079 & -0.15 & 0.2080 & -0.10 & 0.2076 & -0.29 \\
& 1750 & 0.2097 & -0.20 & 0.2097 & -0.20 & 0.2097 & -0.20 \\
& 1800 & 0.2117 & -0.16 & 0.2117 & -0.16 & 0.2123 & +0.12 \\
& 1850 & 0.2140 & +0.02 & 0.2142 & +0.12 & 0.2154 & +0.67 \\
\hline \multirow{4}{*}{$\beta$} & 2150 & 0.1952 & -0.13 & 0.1956 & +0.07 & 0.1950 & -0.24 \\
& 2200 & 0.1976 & +0.07 & 0.1975 & +0.02 & 0.1978 & +0.18 \\
& 2250 & 0.2002 & +0.20 & 0.1993 & -0.26 & 0.2007 & +0.44 \\
& 2300 & 0.2028 & +0.13 & 0.2012 & -0.66 & 0.2038 & +0.62 \\
& 2350 & - & - & 0.2037 & -0.94 & 0.2055 & -0.06 \\
& 2400 & - & - & 0.2079 & -0.56 & 0.2113 & +1.06 \\
\hline
\end{tabular}

${ }^{\text {a }}$ Specific heat is in $\mathrm{J} \cdot \mathrm{g}^{-1} \cdot \mathrm{K}^{-1}$, and the quantity $\Delta c_{p}$ is percentage deviation of the individual results from the smooth functions represented by the pertinent eqs in table 3 .

\section{References}

[1] Cezairliyan, A., Design and operational characteristics of a high-speed (millisecond) system for the measurement of thermophysical properties at high temperatures, J. Res. Nat. Bur. Stand. (U.S.) 75C (Eng. and Instr.), 7 (1971).

[2] Cezairliyan, A., Morse, M. S., Berman, H. A., and Beckett, C. W., High-speed (subsecond) measurement of heat capacity, electrical resistivity, and thermal radiation properties of molybdenum in the range 1900 to $2800 \mathrm{~K}$, J. Res. Nat. Bur. Stand. (U.S.) 74A (Phys. and Chem.), No. 1, 65 (Jan.-Feb. 1970).

[3] International Practical Temperature Scale of 1968, Metrologia 5, 35 (1969).

[4] Foley, G. M., High-speed optical pyrometer, Rev. Sci. Instr. 41, 827 (1970).

[5] Arutyunov, A. V., Banchila, S. N. and Filippov, L. P., Thermal, electrical and emissive properties of hafnium in the hightemperature region, High Temperature 10, 375 (1972).

[6] Peletskii, V. E. and Druzhinin, V. P., Experimental study of some physical properties of hafnium at high temperatures, High Temperature 9, 490 (1971).

[7] Hawkins, D. T., Onillon, M. and Orr, R. L., High-temperature heat content of hafnium, J. Chem. and Eng. Data 8, 628 (1963).
TABLE A-2. Experimental results on electrical resistivity of hafnium-3 (wt. \%) zirconium ${ }^{\text {a }}$

\begin{tabular}{|c|c|c|c|c|c|c|c|}
\hline \multirow{3}{*}{ Phase } & \multirow{3}{*}{$\underset{(\mathbf{K})}{\text { Temp. }}$} & \multicolumn{4}{|c|}{ Specimen-1 } & \multirow{2}{*}{\multicolumn{2}{|c|}{ Specimen-2 }} \\
\hline & & \multicolumn{2}{|c|}{ First heating } & \multicolumn{2}{|c|}{ Second heating } & & \\
\hline & & $\rho$ & $\Delta \rho$ & $\rho$ & $\Delta \rho$ & $\rho$ & $\Delta \rho$ \\
\hline \multirow{11}{*}{$\alpha$} & 1500 & 158.97 & +0.02 & 159.52 & +0.36 & 157.94 & -0.63 \\
\hline & 1550 & 160.54 & +0.12 & 160.96 & +0.38 & 159.61 & -0.46 \\
\hline & 1600 & 161.85 & +0.15 & 162.15 & +0.33 & 161.02 & -0.36 \\
\hline & 1650 & 163.02 & +0.18 & 163.21 & +0.30 & 162.39 & -0.20 \\
\hline & 1700 & 163.92 & +0.15 & 164.02 & +0.21 & 163.35 & -0.20 \\
\hline & 1750 & 164.65 & +0.10 & 164.66 & +0.11 & 164.15 & -0.20 \\
\hline & 1800 & 165.23 & +0.04 & 165.16 & +0.01 & 164.79 & -0.21 \\
\hline & 1850 & 165.65 & 0.00 & 165.54 & -0.07 & 165.28 & -0.22 \\
\hline & 1900 & 166.10 & +0.05 & 165.94 & -0.04 & 165.82 & -0.11 \\
\hline & 1950 & 166.36 & +0.08 & 166.14 & -0.05 & 166.09 & -0.08 \\
\hline & 2000 & 166.57 & +0.17 & 166.30 & +0.01 & 166.37 & +0.06 \\
\hline \multirow{8}{*}{$\beta$} & 2050 & 153.93 & +0.22 & $=$ & - & 153.33 & -0.17 \\
\hline & 2100 & 154.34 & +0.12 & 154.53 & +0.25 & 153.68 & -0.30 \\
\hline & 2150 & 154.83 & +0.08 & 154.83 & +0.08 & 154.26 & -0.29 \\
\hline & 2200 & 155.44 & +0.10 & 155.42 & +0.09 & 154.87 & -0.26 \\
\hline & 2250 & 156.01 & +0.11 & 156.02 & +0.12 & 155.49 & -0.22 \\
\hline & 2300 & 156.55 & +0.09 & 156.63 & +0.14 & 156.13 & -0.18 \\
\hline & 2350 & & & 157.26 & +0.08 & 156.70 & -0.17 \\
\hline & 2400 & & & 157.76 & +0.14 & 157.30 & -0.15 \\
\hline
\end{tabular}

a Electrical resistivity is in $10^{-8} \Omega \cdot \mathrm{m}$, and the quantity $\Delta \rho$ is percentage deviation of the individual results from the smooth functions represented by the pertinent eqs in table 3 .

[8] Zhorov, G. A., Emissivity of metals of the IV b subgroup at high temperatures, High Temperature 8, 501 (1970).

[9] Bedford, R. G., High-temperature electrical resistivity and allotropic transformation temperature of hafnium, J. Appl. Phys. 36, 113 (1965).

[10] Cezairliyan, A. and McClure, J. L., Temperature and energy of $\alpha \rightarrow \beta$ transformation in hafnium-3 (wt \%) zirconium, in preparation.

[11] Cezairliyan, A. and Righini, F., Simultaneous measurements of heat capacity, electrical resistivity and hemispherical total emittance by a pulse heating technique: zirconium, 1500 to 2100 K, J. Res. Nat. Bur. Stand. (U.S.), 78A (Phys. and Chem.), No. 4, 509 (July-Aug. 1974).

[12] Fast, J. D., The allotropic transformation of hafnium and a tentative equilibrium diagram of the system zirconiumhafnium, J. Appl. Phys. 23, 350 (1952).

[13] Atomic Weights of the Elements, 1969, Pure and Appl. Chem. 21, 91 (1970). 